\title{
A QUÍMICA DE PRODUTOS NATURAIS APLICADOS A REVELADORES DE IMPRESSÕES DIGITAIS LATENTES
}

\author{
Amanda F. Leitzkea, Lucas M. Berneira ${ }^{a}$, Bruno N. da Rosa ${ }^{a}$, Bruna C. Moreira ${ }^{a}$, Kristiane de C. Mariotti ${ }^{\mathrm{b}}$ Dalila Venzke, \\ e Claudio M. P. Pereira ${ }^{a, *,(i)}$ \\ aCentro de Ciências Químicas, Farmacêuticas e de Alimentos, Universidade Federal de Pelotas, 96010-900, Pelotas - RS, Brasil \\ bNúcleo de Identificação, Polícia Federal, 90610-093, Porto Alegre - RS, Brasil
}

Recebido em 17/08/2021; aceito em 28/10/2021; publicado na web em 18/11/2021

\begin{abstract}
THE CHEMISTRY OF NATURAL PRODUCTS APPLIED TO LATENT FINGERMARK DEVELOPERS. Natural formulations have attracted great interest of many researchers regarding their use as latent fingermark developers powders due their important characteristics as the presence of natural pigments in these materials that offer a good contrast on the applied surface and also luminescent properties, which facilitates the visualization of minutiae in problematic substrates such as multicolored surfaces. In addition, natural powders present low toxicity, are widely available and economically viable. In this sense, the present work addresses the application of several natural products to enhance fingermarks visualization. The natural products were obtained from various sources such as seaweed, spices as well as other sources such as terrestrial and herbaceous plants. The evaluated powders are composed by compounds as chlorophyll, phycocyanins, curcumins, lawsone, fatty acids, coumarins, flavonoids and terpenes. These powders showed good adhesion to latent fingermarks, with similar or superior efficiency to the available powders on different surfaces with clear visualization of the minutiae. The development of new powders applicable to papiloscopy are extremely important since the conventional available powders, besides being expensive, are imported and within the national context there is a great lack of these revealing materials within forensic investigations by the Federal Police and in laboratories of research.
\end{abstract}

Keywords: natural pigments; forensic chemistry; powder dusting; latent fingermarks.

\section{INTRODUÇÃO}

As impressões digitais são definidas como um resíduo encontrado em superfícies que foram tocadas por um indivíduo com as mãos desprotegidas. ${ }^{1}$ Essas impressões são notavelmente únicas para cada indivíduo e podem ser usadas como ferramenta primária de identificação humana em investigações forenses. ${ }^{2}$

As impressões digitais podem ser divididas em três classes: latentes, patentes ou plásticas. ${ }^{3}$ As impressões digitais latentes são as mais encontradas em cenas de crime e por serem invisíveis a olho nu necessitam de técnicas adequadas de revelação. ${ }^{3}$ Ao longo das décadas, muitos investigadores exploraram novos e aprimorados métodos para o desenvolvimento e recuperação de impressões digitais latentes. ${ }^{4,5}$ As técnicas mais comumente utilizadas são: método do empoamento, spray de ninidrina, vapor de iodo e imersão em nitrato de prata. ${ }^{4}$

A técnica do empoamento é relativamente simples e envolve a aplicação de um material finamente dividido e subseqüente remoção do excesso com auxílio de pincéis. ${ }^{6}$ A aderência do pó ao resíduo de impressão digital para fornecer boa visibilidade e definição dos detalhes da impressão digital. ${ }^{7}$ Em geral, essa técnica baseia-se na aderência mecânica ou física dos pós com os componentes úmidos e oleosos dos resíduos das impressões digitais depositados nos substratos. ${ }^{7,8}$

A maioria dos pós comerciais contém dois elementos essenciais para fornecer boa adesão aos resíduos da impressão digital, que são o pigmento e o aglutinante. O pigmento no pó de revelação oferece um bom contraste entre a impressão digital e o substrato, enquanto o aglutinante fornece adesão máxima e preferencial dos resíduos da impressão digital latente. ${ }^{7}$ Em geral os pós de revelação

*e-mail: lahbbioufpel@gmail.com

\#e-mail alternativo: venzke.dalila@gmail.com são classificados em quatro grupos que são os pós regulares, luminescentes, metálicos e termoplásticos. ${ }^{4}$

Além disso, outros fatores como o tamanho das partículas, forma, área de superfície relativa e carga das partículas, a adesão a componentes oleosos ou líquidos e menor adesão ao substrato também são importantes na adesão dos pós nos resíduos das impressões papilares. $^{9}$

Os pós tradicionalmente utilizados pela técnica do empoamento frequentemente se mostram limitados em alguns tipos de superfícies e também podem trazer problemas à saúde dos profissionais que os utilizam por longos períodos. ${ }^{4}$ Tais problemas mostraram a necessidade de desenvolver reveladores de impressões digitais que possuam pouca ou nenhuma toxicidade e uma aderência mais eficaz aos diferentes tipos de superfícies em que é possível encontrar impressões digitais latentes. ${ }^{4,10}$

Diante desse contexto, os produtos naturais tem se mostrado uma matéria prima alternativa na revelação de impressões digitais latentes. ${ }^{7,8}$ Muitos produtos naturais contêm cromóforos em suas estruturas químicas capazes de conferir atrativas colorações a esses compostos. ${ }^{11}$ Os principais pigmentos naturais são os carotenóides, iridoides, purinas, pterinas, flavinas, fenazinas, fenoxazinas, betalainas, antocianinas, quinonas, melaninas, clorofilas e flavonoides. ${ }^{11}$ A presença desses pigmentos naturais em formulações de pós é muito importante no que concerne a visualização de impressões digitais latentes uma vez que esses pigmentos formam um bom contraste com as superfícies aplicadas. ${ }^{7,8}$ Além disso, produtos naturais apresentam baixa toxicidade em relação aos convencionais reveladores de impressões digitais, possuem propriedades medicinais, são de fácil acesso e a sua matéria-prima é barata. ${ }^{7,8}$

Nesse sentido, muitas formulações derivadas de plantas herbáceas e algas marinhas foram estudadas quanto ao seu desempenho na visualização de impressões digitais. ${ }^{7,8,12} \mathrm{O}$ presente artigo de revisão 
tem como objetivo fornecer uma revisão da literatura científica abordando a utilização de pós obtidos de produtos naturais e sua aplicação forense na revelação de impressões digitais latentes em diferentes superfícies.

\section{UM BREVE HISTÓRICO DOS CORANTES NATURAIS}

Os produtos naturais vêm sendo utilizados pelo ser humano desde sua antiguidade. Desde o desenvolvimento das primeiras civilizações, os recursos naturais ganharam grande apelo devido ao conhecimento de alguns produtos com funcionabilidade medicinal. ${ }^{13}$ Primariamente, a utilização de plantas medicinais funcionava de maneira totalmente empírica e se baseava em descobertas acidentais. ${ }^{14}$

Nas últimas décadas, tentativas de se entender melhor os mecanismos de atuação de compostos naturais, a fim de conciliá-los à medicina moderna, têm possibilitado o êxito de pesquisas referentes à utilização farmacológica de princípios ativos de origem vegetal, colocando os produtos naturais em posição de destaque na área de desenvolvimento de fármacos. ${ }^{15}$ Os princípios ativos pertencentes à grande variedade de espécies que os reinos Plantae, Chromista e Protozoa possuem, ainda são estudados pela química moderna como uma alternativa para o tratamento de doenças e/ou outras anomalias do corpo humano. ${ }^{16}$

Ainda dentro do contexto histórico dos produtos naturais, outro papel importante que esses apresentavam nas antigas civilizações era seu uso como corante natural, sendo utilizados como uma espécie de "tinta" da época, o que facilitava a comunicação e expressão artística. São exemplos de corantes naturais da época a bixina, a andirobina e a genipina (Figura 1). ${ }^{13,16}$

A bixina é o principal corante extraído dos frutos da bixácea (Bixa orellana L.) mais conhecida como urucum. Esse produto natural apresenta pigmentação vermelha e pertence à classe química dos carotenoides. ${ }^{17,18} \mathrm{~A}$ andirobina também é um corante vermelho pertencente a classe dos tetranortriterpenos e pode ser extraída da espécie Carapa guianensis. ${ }^{13,19} \mathrm{~A}$ genipina por sua vez muito utilizado pelos indígenas, sendo obtido da seiva do fruto do jenipapo cujo nome botânico é Genipa americana. As tatuagens de cores pretas, que impressionavam os colonizadores, eram feitas com essa Rubiaceae, e o iridoide conhecido como genipina é o responsável pela sua coloração. ${ }^{18,20}$ Apesar de ser incolor em si, esse iridoide produz cor preta após reagir com as proteínas da pele (Figura 1). ${ }^{21}$<smiles>COC(=O)/C=C/C(C)=C\C=C\C(C)=C\C=C\C=C(C)\C=C\C=C(C)\C=C\C(=O)O</smiles>

Bixina<smiles>C=C1C([C@]2(C)CCC(=O)C(C)(C)[C@@H]2CC(=O)OC)CC[C@@]2(C)[C@H](c3ccoc3)OC(=O)C3OC132</smiles>

Andirobina<smiles>COC(=O)C1=CO[C@@H](O)[C@H]2C(CO)=CC[C@H]12</smiles>

Genipina
Figura 1. Estrutura química da bixina, genipina e andirobina
No Brasil, uma matéria prima que apresentou destaque economicamente durante o período pré-colonial foi o Pau-Brasil (Paubrasilia echinata). Trata-se de uma espécie arbórea nativa da Mata Atlântica, da qual era extraído uma resina de coloração vermelha devido a presença dos compostos brasilina e brasileína (Figura 2), utilizados como corantes naturais. ${ }^{13}$<smiles>Oc1ccc2c(c1)OCC1(O)Cc3cc(O)c(O)cc3C21</smiles>

Brasilina<smiles>O=C1C=C2C(=O)C=C3CC(O)(COc4cc(O)ccc43)C2=C=C1O</smiles>

Brasileína
Figura 2. Estrutura química da brasileína e brasilina

Nas sociedades modernas, um dos corantes mais utilizados na indústria cosmética é a camomila, de tal forma que xampus de camomila podem ser encontrados em drogarias e supermercados em todo o mundo. As principais espécies de camomilas são a Anthemis nobilis e a Matricaria chamomilla, ambas da família Asteraceae, sendo essa última usada na produção de xampus. Os sesquiterpenos derivados do azuleno estão entre os principais metabólitos encontrados nessas espécies (Figura 3). ${ }^{22}$

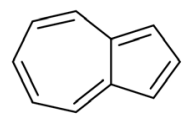

Azuleno

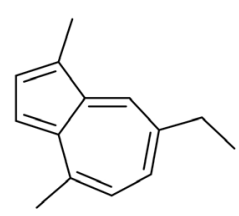

Camazuleno

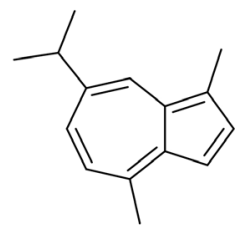

Guaiazuleno
Figura 3. Estrutura química dos sesquiterpenos derivados do azuleno: camazuleno e guaiazuleno

De forma análoga, outros tipos de corantes utilizados em alimentos são as clorofilas. ${ }^{23}$ Elas são os pigmentos naturais mais abundantes presentes nas plantas, muito comuns em legumes e em várias frutas. ${ }^{23}$ Devido a sua cor e as propriedades físico-químicas, são frequentemente utilizadas como aditivos para produtos alimentícios. Em geral, as clorofilas são relativamente instáveis e sensíveis à luz, aquecimento, oxigênio e a degradação química. ${ }^{23}$ As clorofilas são moléculas formadas por complexos derivados da porfirina, tendo como átomo central o magnésio. Seus pigmentos podem ser quimicamente modificados antes de serem incorporados aos alimentos, como, por exemplo, substituindo o $\mathrm{Mg}^{2+}$ por $\mathrm{Cu}^{2+}$ na clorofila. Precursores e derivados das clorofilas também são usados na medicina para tratamentos fotodinâmicos. ${ }^{23,24}$

Ao tratar de condimentos, é possível citar a canela. As canelas são uma das espécies vegetais mais antigas conhecidas pela humanidade. A mais conhecida é a Cinnamomum zeylanicum, nativa do Ceilão, atual Sri Lanka. A canela já foi uma das especiarias mais valiosas do mundo, de tal forma que o seu valor chegou a ser 15 vezes maior que o do ouro na Idade Média. Outras, entretanto, como a Cassia (Cinnamomum cassia), também conhecida como falsa canela e canela da China, têm importância econômica até os dias atuais. ${ }^{25}$

Muitos condimentos contêm corantes naturais em sua composição, o que confere uma coloração bem característica a essa matéria prima. Um exemplo é o corante curcumina extraído da espécie Curcuma longa $L .{ }^{8}$ Essa espécie também foi avaliada quanto ao seu desempenho 
como revelador de impressão digital. A presença do componente majoritário curcumina, principal responsável pela sua pigmentação, torna a cúrcuma um potencial revelador. ${ }^{8}$

A utilização de corantes naturais acompanha a história da humanidade. Seu potencial de aplicação abrange a indústria alimentícia, cosmética e farmacêutica. Mais recentemente observa-se no meio científico o crescente interesse pelo emprego desse tipo de matéria prima no meio forense, especialmente no desenvolvimento de pós reveladores aplicáveis a análise de impressões digitais. Dentre as justificativas cita-se que esses corantes, de maneira geral, apresentam bom contraste com superfície aplicada devida a variedade de colorações possíveis, facilidade de acesso, baixo custo e baixa toxicidade. ${ }^{7,8,12,26}$

Nos próximos itens serão relatados com mais detalhes alguns produtos naturais de grande relevância na área de desenvolvimento de pós reveladores de impressões digitais.

\section{APLICAÇÃO DE PRODUTOS NATURAIS NA REVELAÇÃO DE IMPRESSÕES DIGITAIS LATENTES}

\section{Algas marinhas}

As algas marinhas constituem uma classe de organismos aquáticos fotossintéticos. É estimado cerca de 300 mil espécies de algas no mundo, sendo esse número muito superior comparadas as espécies de plantas terrestres conhecidas. ${ }^{27}$ Em relação a sua organização celular, as algas podem ser divididas em unicelulares (microalgas) e multicelulares (macroalgas). Além disso, as algas podem ser divididas em grupos majoritários conforme a sua taxonomia, podendo ser: cianobactérias (Cyanophyceae); algas verdes (Chlorophyceae); diatomáceas (Bacillariophyceae); algas amarelas-verdes (Xanthophyceae); algas douradas (Chrysophyceae); algas vermelhas (Rhodophyceae); algas marrons (Phaeophyceae); dinoflagelados (Dinophyceae) e picto-planctons (Prasinophyceae e Eustigmatophyceae). ${ }^{28}$

As algas marinhas são conhecidas por ser fonte de diversos compostos bioativos associados a metabolitos primários e secundários. ${ }^{29}$ As algas contém três principais componentes: proteínas, carboidratos e lipídeos. A concentração dos compostos químicos pode variar conforme a espécie, sendo a concentração de ácidos graxos até $40 \%$ da porcentagem total das algas..$^{28}$ Atualmente, diversas aplicações são encontradas para as algas marinhas dentro dos setores industriais, como nas áreas de biocombustíveis, biofertilizantes, biorremediação do solo, tratamento de águas residuais e biomateriais, além de sua aplicação na alimentação humana e animal. ${ }^{28}$

A utilização de algas marinhas como reveladores de impressões digitais latentes foi introduzida por King e colaboradores, ${ }^{26}$ que avaliaram a eficácia de revelação de impressões digitais naturais com a biomassa da alga Spirulina platensis em diferentes tipos de superfícies. Para o estudo foram coletadas impressões digitais de 12 doadores com idades variando de 28 a 50 anos. A intensidade de fluorescência da microalga $S$. platensis foi comparada com outros produtos naturais que apresentam clorofila e/ou antocianinas em sua composição, que são conhecidos por apresentarem fluorescência na região do infravermelho-próximo. Clorofila é um pigmento natural, presentes nas plantas, capaz de absorver luz e garantir a alimentação dos organismos fotossintéticos (Figura 4) ${ }^{26,30}$ A clorofila possui forte absorção na região azul e vermelha do espectro infravermelho, enquanto emite forte fluorescência no infravermelho-próximo. ${ }^{26,30}$ Sabe-se que um dos pontos cruciais na análise de impressão digitais latentes é a escolha de um revelador que possua coloração que contraste com a superfície em que a marca está depositada. Nas situações em que o substrato contém mais de uma cor, uma alternativa é o uso de reveladores luminescentes, que acaba por destacar a impressão digital do restante do substrato quando utilizados filtro e luz adequados para a sua visualização. ${ }^{26,29}$

A biomassa $S$. platensis teve resultados mais promissores em relação às outras biomassas avaliadas (grama de trigo, brócolis e moringa) que apresentaram significativa redução na fluorescência acima de $850 \mathrm{~nm}$. Ao aplicar a luminescência houve um aumento na resolução devido ao aumento do contraste entre a biomassa e a superfície testada. Essa espécie é composta quimicamente não somente por uma grande quantidade de clorofila, mas também por quantidades significativas de ficocianinas. ${ }^{26} \mathrm{~A}$ excitação combinada de Spirulina platensis tanto nas regiões azul e vermelha do espectro combinada com fluorescência intensa acima de $800 \mathrm{~nm}$, torna esse material promissor para seu uso como pó de revelação de impressões digitais. ${ }^{26,29}$

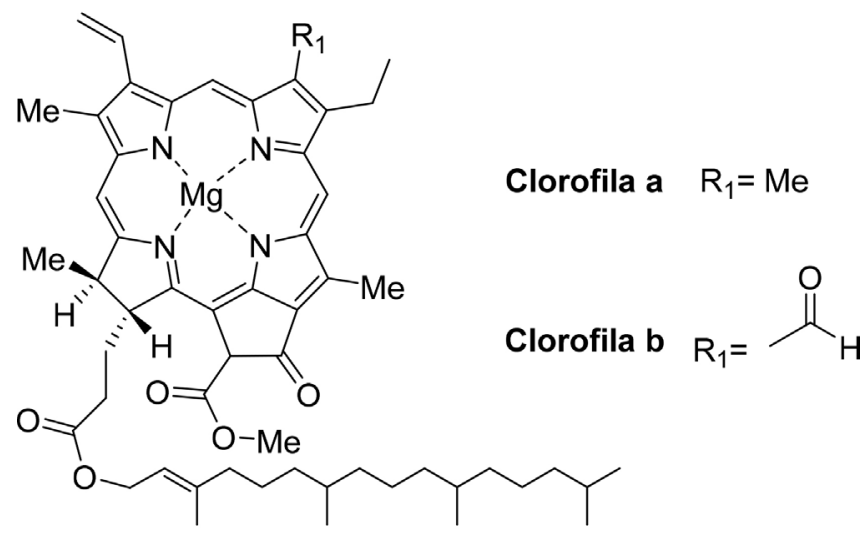

Figura 4. Estrutura química dos pigmentos clorofila a e $b$

Nesse estudo o tamanho de partícula das amostras comerciais foi reduzido em um sistema de moinho de bolas, onde foi observado que à medida que o tamanho de partícula era reduzido, a fluorescência do pó era intensificada. ${ }^{26}$ Os ensaios de revelação mostraram que o pó com o tamanho de partícula de $30 \mathrm{~mm}$ foi o mais eficiente na visualização das impressões digitais. Os substratos neste trabalho foram escolhidos com base na sua adequação para pulverização (ou seja, tipicamente não porosos), bem como sua natureza problemática em termos de ser capaz de identificar e revelar claramente uma impressão digital como que ocorre com os pós convencionais luminescentes. Foram utilizados materiais como metais tratados e não tratados, plástico, vidro e cerâmica vidrada, dando ênfase a itens altamente coloridos ou multicoloridos. ${ }^{26}$

As imagens obtidas com o uso do pó de Spirulina como revelador mostraram apreciável contraste em fundo branco, cinza ou preto com o uso de luz branca ou halógena, considerando a cor verde do pó de revelação. No entanto, como ocorre com outros pós de revelação, o contraste mostrou ser problemático com o uso de luz branca em fundos multicoloridos, onde apenas algumas partes das marcas de impressões digitais foram visíveis. Ao utilizar luz vermelha (600$650 \mathrm{~nm}$ ) e filtro de longa passagem a $780 \mathrm{~nm}$, pode-se observar as marcas papilares com excelente contraste com fluorescência no Infravermelho-próximo. Essa propriedade foi extendida a outras regiões do espectro pela mudança dos filtros de longa passagem para 800,850 e $1000 \mathrm{~nm}^{26}$

A fluorescência no infravermelho-próximo apresentada pelo pó testado mostrou contornar alguns problemas com alguns substratos como papéis de embrulho e cédulas de polímero que são difíceis de revelar devido a sua semi-porosidade e interferência da fluorescência das tintas impressas neles. Os resultados de revelação mostraram impressões digitais altamente resolvidas em dois tipos de cédulas de 
polímero utilizando o pó de Spirulina. Dessa forma, o pó avaliado mostrou-se um excelente revelador além de possuir baixa toxicidade, podendo ser utilizado em diferentes substratos encontrados em cenas de crime. ${ }^{26}$

Posteriormente, Passos e colaboradores ${ }^{12}$ avaliaram as características físicas e químicas das algas marinhas como uma alternativa na utilização de biomassa como revelador de impressão digital latente. Nesse trabalho foram avaliadas micro e macroalgas, bem como a variação na classificação taxonômica entre as espécies, além de parâmetros, como composição química e tamanho de partícula, que podem ser fundamentais na escolha do material mais adequado para a elucidação da impressão digital latente. ${ }^{12}$

Dentre as algas estudadas no trabalho, duas microalgas (Chlorella e Spirulina) e três macroalgas (Desmarestia anceps, Laurencia dendroidea e Lessonia searlesiana) foram utilizadas. A análise cromatográfica por Cromatografia a gás acoplada a Espectrometria de Massas (CG-EM) das espécies em estudo permitiu a identificação de aproximadamente 40 compostos de diferentes classes como ácidos carboxílicos, aminas, hidrocarbonetos, esteróis e alcoóis. Em geral, os ácidos carboxílicos foram encontrados como grupos majoritários no gênero Chorella enquanto os alcoóis prevaleceram em outras biomassas marinhas. ${ }^{12}$

Nos ensaios de deposição de impressão digital foram selecionados quatro doadores (dois homens e duas mulheres), sendo coletadas secreções naturais e sebáceas.

Passos e colaboradores ${ }^{12}$ também observaram uma variação na qualidade dos pós avaliados em relação à adesão às impressões digitais latentes. Como reportado previamente por King e colaboradores, ${ }^{26} \mathrm{o}$ pó de Spirulina sp. mostrou-se eficiente na revelação de impressões digitais latentes naturais e sebáceas com clara visualização das minúcias, mostrando os melhores resultados dentre todas as algas avaliadas. L. Searlesiana, Chlorella sp. e L. dendroidea também se mostraram eficientes na visualização das impressões digitais naturais enquanto a espécie $D$. anceps não mostrou resultados satisfatórios. Em relação aos ensaios com as secreções sebáceas, todas as algas avaliadas mostraram eficiência na adesão às marcas papilares, sendo que a Spirulina sp. mostrou os melhores resultados seguido por Chlorella sp. e L. dendroidea que mostraram resultados intermediários e $D$. anceps que mostrou a menor eficiência de revelação. Segundos os autores, os constituintes químicos presentes nas biomassas mostraram melhor interação com os compostos presentes nas secreções sebáceas, devido à melhor qualidade de imagens obtidas com esse tipo de impressão digital. Além disso, a biomassa de Spirulina não mostrou diferenças consideráveis nesse estudo em relação ao revelador comercial verde fluorescente na revelação de impressões digitais latentes naturais e sebáceas. ${ }^{12}$

Os autores também destacaram que vários parâmetros podem influenciar a eficácia dos pós reveladores de impressões digitais latentes. Nesse sentido, fatores como tamanho de partícula, carga eletrostática e composição química são fatores determinantes para caracterizar os reveladores de impressões digitais. Deve-se notar que o pó revelador deve ter menor adesão ao substrato e aos contaminantes potenciais, a fim de melhorar a adesão do pó às impressões digitais latentes e assim revelá-las com maior eficiência, facilitando o processo de identificação de minúcias. ${ }^{4,29}$

A Figura 5 ilustra as principais etapas de coleta de impressões digitais latentes naturais e sebáceas e sua revelação. Na coleta de das impressões digitais naturais, o doador é orientado a lavar suas mãos com sabão neutro e seguir suas atividades normalmente por um determinado período de tempo (geralmente trinta minutos) para então depositá-las. Já na deposição das impressões sebáceas o doador é orientado a friccionar os dedos em locais oleosos, como testa e nariz e então realizar a deposição das impressões digitais. Após essas coletas, aguarda-se um período (que varia de acordo com o estudo que se deseja realizar) para fazer a revelação das impressões digitais pelo método do empoamento, utilizando-se pincéis específicos e os pós selecionados. Em seguida, é feita a captura das imagens das impressões digitais reveladas. A técnica do empoamento é relativamente simples e o uso de produtos naturais como reveladores de impressões digitais latentes é muito viável economicamente, pois apresentam baixo custo, são amplamente disponíveis e apresenta baixa toxicidade quando comparados aos reveladores tadicionais disponíveis no mercado que além de serem tóxicos muitas vezes são importados e apresentam alto custo.
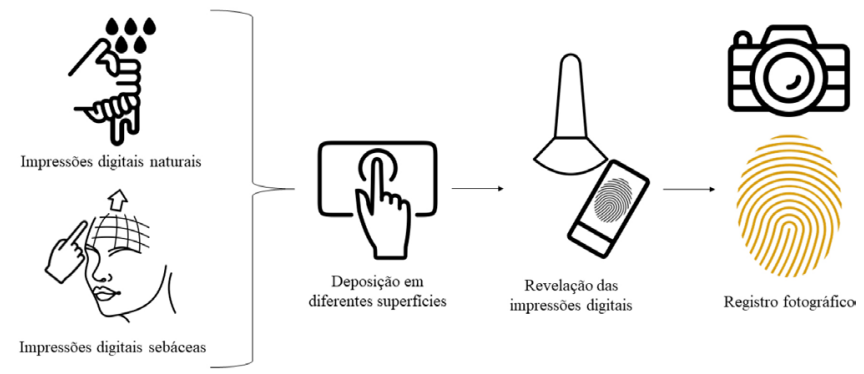

Figura 5. Etapas de deposição e revelação de impressões digitais latentes

Ao fazer uma busca nos periódicos CAPES na base de dados Web of Science usando as palavras "natural dyes fingerprint" aparecerem 145 resultados na busca e ao utilizar as palavras "ninhydrin fingerprint" e "cyanoacrylate fingerprint" aparecerem 178 e 150 resultados respectivamente. Esses dados mostram que a contribuição de pigmentos naturais é bem expressiva no que tange a busca por novos reveladores de impressões digitais quando comparados aos reveladores clássicos como ninidrina e cianoacrilato.

\section{Condimentos}

A espécie Curcuma longa, conhecida popularmente como açafrão, constitui uma espécie de erva rizomatosa do gênero Curcuma. Existem cerca de 70 espécies de Curcuma distribuídas pelo mundo, nas regiões tropicais e subtropicais, com predominância nos países asiáticos, em especial a India. ${ }^{31}$ A Curcuma longa possui uma coloração amareloescuro, devido à presença de curcuminoides, que se apresentam na forma de curcumina, desmetoxicurcumina e bis-desmetoxicurcumina (Figura 6). Além disso, as curcuminas são conhecidas pelo seu potencial antioxidante, anti-inflamatório, antiparasitário, antialérgico, antimicrobiano e antimutagênico. Também possuem atividade na prevenção de câncer e no tratamento de HIV. ${ }^{32-36}$

A curcumina, como revelador de impressão digital latente, foi estudada pela primeira vez por Garg e colaboradores. ${ }^{8}$ Os autores avaliaram a interação do açafrão com as impressões digitais latentes sebáceas em superfícies porosas e não porosas. Nos ensaios de deposição foram coletadas onze impressões digitais sebáceas coletadas no rosto e testa. Os tipos de superfícies empregados nessa investigação foram: papel normal, papel bond, papel térmico, papel transparente, folha de alumínio, madeira, folha de plástico, aço pintado e superfície de um CD. Para a revelação de impressões digitais, o rizoma de açafrão foi obtido comercialmente e moído. A técnica utilizada para a revelação das impressões digitais foi o método do empoamento, onde poucos gramas do pó moído de açafrão foram espalhadas nas superfícies com as deposições de impressão digital, sendo o excesso de pó removido. O revelador apresentou resultados satisfatórios para todas as superfícies testadas. Os autores descrevem que a razão da aderência do pó revelador com as secreções das impressões digitais latentes sebáceas está relacionada com a formação de ligações de 
<smiles>COc1cc(/C=C/C(=O)CC(=O)/C=C/c2ccc(O)c(OC)c2)ccc1O</smiles>

Curcumina (Curcumina I)<smiles>COc1cc(/C=C/C(=O)CC(=O)/C=C/c2ccc(O)cc2)ccc1O</smiles>

Desmetoxicurcumina (Curcumina II)<smiles>O=C(/C=C/c1ccc(O)cc1)CC(=O)/C=C/c1ccc(O)cc1</smiles>

\section{Bis-desmetoxicurcumina (Curcumina III)}

Figura 6. Estrutura química da curcumina, desmetoxicurcumina e bisdesmetoxicurcumina

hidrogênio entre os ácidos graxos e glicídios das impressões digitais com o grupo carbonila e hidroxila da curcumina oriunda do pó de açafrão. ${ }^{8}$ Esse estudo relata uma investigação preliminar e salienta que testes acerca do desenvolvimento de impressões digitais em condições de umidade e temperatura diversas, variação sazonal e avaliação comparativa com outros agentes químicos precisam ser feitos.

Geralmente, o pó apresenta uma ampla afinidade com a umidade presente nos compostos da impressão digital, ou seja, quanto mais recente a impressão maior será a adesão do pó revelador sobre as partículas de água presente. ${ }^{37,38}$ Essa revelação ocorre devido ao fenômeno de adsorção que é caracterizado pela fixação das moléculas do pó (o adsorvato) na superfície contendo a impressão digital (o adsorvente). Ao passar do tempo, os compostos que vão permanecendo nas impressões digitais são os sebáceos, de forma que a interação entre esses compostos e o pó revelador ocorre através de forças de van der Waals e ligações de hidrogênio. ${ }^{37}$

Outra técnica empregada para revelação de impressões digitais latentes é a que utiliza cristais de iodo. Através desse metodologia, os cristais de iodo sofrem um processo de transformação física (sublimação), quando absorvem calor e passam do estado sólido diretamente para o estado de vapor. ${ }^{37} \mathrm{O}$ vapor do iodo, de coloração violeta, interage com o material sebáceo presente na impressão digital de forma a realizar um processo de halogenação reversível na amostra, visto que o iodo interage com as ligações duplas presentes em lipídeos como também em outros constituintes que tenham instaurações na composição das impressões digitais. ${ }^{39}$

Por sua vez, o reagente nitrato de prata $\left(\mathrm{AgNO}_{3}\right)$ foi um dos primeiros agentes utilizados para revelar impressões digitais latentes em substratos porosos. ${ }^{38} \mathrm{O}$ princípio do método de revelação está fundamentado em uma reação química, sendo que, o nitrato de prata reage com íons cloreto como, por exemplo, o cloreto de sódio $(\mathrm{NaCl})$, que estão presentes nos componentes das impressões digitais latentes formando o cloreto de prata $(\mathrm{AgCl})$, que ao ser exposto a uma fonte de luz, decompõe-se formando prata metálica $(\mathrm{Ag})$, resultando em uma impressão digital revelada na coloração preta. ${ }^{38,40}$

Poletti e colaboradores ${ }^{41}$ mostraram que a aplicação de métodos de pó permitiu uma eficiência de desenvolvimento durante o envelhecimento de impressões digitais até 30 dias. Entre os motivos que poderiam explicar esses resultados no envelhecimento inicial de
1 a 2 dias estavam a adesão do pó à umidade presente nas marcas latentes dos dedos. ${ }^{37,38}$ Ao longo do envelhecimento de 4 a 30 dias, a umidade presente nas impressões digitais latentes evaporou e os constituintes sebáceos restantes interagiram com os pós através de interações van der Waals e ligações de hidrogênio mantendo uma eficiência constante em todo o período testado. ${ }^{37}$

Em relação ao método dos cristais de iodo, foi possível observar que nas fases iniciais do envelhecimento (até 1 dia) o desenvolvimento e visualização das cristas papilares foram eficazes. Isso ocorreu devido à interação dos vapores de iodo com as duplas ligações do material sebáceo presente nas marcas dos dedos ocorrendo uma halogenação reversível. ${ }^{39}$ Ao longo do envelhecimento de 2 a 30 dias, a constituição das marcas alterou-se devido às condições ambientais, o que fez com que a sua composição degradasse tornando o desenvolvimento de latentes marcas de dedo com cristais de iodo cada vez mais difíceis. ${ }^{42-45}$

$\mathrm{O}$ oposto ocorreu com o uso do método do nitrato de prata, pois a eficiência de desenvolvimento aumentou com o envelhecimento. O principal motivo que poderia explicar esse comportamento é que, ao longo do envelhecimento, a umidade começou a diminuir em marcas latentes de dedos aumentando as concentrações de compostos sebáceos e sais como o cloreto de sódio. ${ }^{38}$ Com o passar do tempo, o aumento da concentração de cloreto de sódio em marcas latentes permitiu sua conversão em cloreto de prata, desenvolvendo de forma eficiente as amostras envelhecidas. ${ }^{38,40}$

Em outro estudo, Adhithya e Suneetha ${ }^{46}$ elaboraram um trabalho de revelação de impressão digital latente onde também utilizaram o açafrão como revelador de impressão digital, além da pimenta chilli, pimenta em pó e carvão na detecção forense.

Os pós avaliados foram moídos com auxilio de pilão e almofariz e foram espalhados sobre a superfície de vidro contendo as impressões digitais utilizando a técnica do empoamento. As impressões digitais foram obtidas pressionando o polegar com secreções sebáceas coletadas da testa firmemente em superfícies de vidro (placas de petri). O excesso de pó foi removido com uma escova e as impressões digitais foram retiradas com fita adesiva de celofane e coladas em folha de papel branca. Com base na observação visual, verificou-se que o pó de carvão ofereceu a revelação com melhor contraste. O pó de cúrcuma apresentou melhor resultado quando comparado ao pó de pimenta preta e pimenta chilli. As cristas eram claramente visíveis quando o carvão e pó de açafrão foram usados. No caso da pimenta chilli e da pimenta em pó, os sulcos não se mostraram tão visíveis. Portanto, o pó de carvão e açafrão foram eficientes na revelação de impressões digitais latentes sebáceas e apresentam baixo custo e toxicidade, além de serem facilmente obtidos. ${ }^{46}$

Em um estudo realizado por Saran e colaboradores, ${ }^{47}$ diferentes pós naturais não tóxicos encontrados na natureza foram utilizados como reveladores de impressões digitais. Pimenta vermelha, cúrcuma (açafrão), calêndula, carvão preto em pó e fuligem de óleo de mostarda foram aplicados nessas superfícies.

A espécie Calendula officinalis L. é uma planta pertencente à família Asteraceae que apresentam flores amarelas ou douradas. Essa espécie é amplamente usada em várias partes do mundo para fins ornamentais, cosméticos e terapêuticos. É muito utilizada na medicina popular e tem sido investigado no tratamento de febre, câncer e como antimicrobiano, anti-inflamatório e tonificante de pele. Nas flores da calêndula foram descritas diferentes classes de fitoquímicos como a presença de óleo volátil, grande quantidade de resinas, mucilagens, diferentes tipos de polissacarídeos e carotenoides, além de saponinas e flavonoides. Os principais flavonoides detectados nas flores de $C$. officinalis L. são a quercetina e rutina, sendo essa última utilizada como marcador para aferir a qualidade da matéria-prima. ${ }^{48,49}$

Nos ensaios de revelação de impressão digital as flores de calêndula foram coletadas e secas por alguns dias e depois mantidas 
na mufla por $15-20$ min. a $550{ }^{\circ} \mathrm{C}$. As flores de calêndula, o açafrão e a pimenta vermelha foram moídos com almofariz e pilão até obter um pó fino. Nos experimentos foram avaliadas setenta e seis amostras de impressões digitais. Os voluntários foram orientados a esfregar os dedos no cabelo, testa ou atrás das orelhas com o intuito de coletar as secreções sebáceas. Os testes para aplicação envolveram superfícies não porosas, como azulejo, plástico, placa de aço inoxidável, vidro, colher, placa de interruptor, placa composta de alumínio, folha de alumínio de uso doméstico e espelho. Os pós foram aplicados nas superfícies pelo método do empoamento, sendo removido o excesso de pó lentamente e em seguida a impressão digital revelada foi fotografada. $^{47}$

O resultado desse trabalho foi semelhante à pesquisa desenvolvida por Garg e colaboradores. ${ }^{8}$ Verificou-se que a fuligem do óleo de mostarda obteve o melhor resultado, seguida por açafrão e posteriormente pelo pó de calêndula. $\mathrm{O}$ pó de açafrão e calêndula mostraram bons resultados em superfícies não porosas exceto que em superfícies de plástico e vidro as cristas papilares não se mostraram claramente visíveis ao utilizar o pó de calêndula. ${ }^{47}$ Já o pó de pimenta vermelha não mostrou resultados satisfatórios nesse estudo. Os estudos apresentados concluíram que esses pós são encontrados facilmente, apresentam custo acessível, não possuem toxicidade e apresentaram resultados satisfatórios nas superfícies não porosas testadas. ${ }^{47}$

Nicolodi e colaboradores ${ }^{50}$ elaboraram um estudo avaliando a capacidade de utilização de condimentos alimentícios, presentes no cotidiano, como material revelador de impressões digitais latentes naturais e sebáceas, depositadas em superfícies de vidro e plástico. $\mathrm{Na}$ deposição das impressões digitais naturais, o doador lavou as mãos com sabão neutro e seguiu suas atividades normalmente por trinta minutos para então fazer a coleta das impressões. Para a coleta de secreções sebáceas o doador friccionou os dedos em locais oleosos, como testa e nariz e então realizou a deposição nas respectivas superfícies. Após essas coletas, aguardou-se $24 \mathrm{~h}$ para realizar a revelação das impressões digitais pelo método do empoamento. Depois de feita a revelação as impressões digitais foram fotografadas para a captura de imagens. ${ }^{50}$

No trabalho, foram testados os condimentos Curcuma longa (cúrcuma), Murraya koenigii L. (curry), Cinnamomum verum J. (canela), Laurus nobilis L. (louro) e Capsicum annuum L. (páprica), todos em forma de pó obtidos comercialmente. No extrato da espécie C. verum foram identificados os componentes químicos ar-tumerona, cumarina, curlona e eugenol, sendo o cinamaldeido o constituinte majoritário e no extrato de $C$. longa foram detectados ar-tumerona, curlona e tumerona. No extrato de $M$. koenigii também foi reportada a presença dos componentes encontrados na cúrcuma (ar-tumerona, tumerona e curlona) e o eugenol. Além disso, no extrato de L. nobilis foram reportados os componentes majoritários ar-tumerona, cumeno, eugenol, curlona e, em menor quantidade, o constituinte cinamaldeído, e no extrato de $C$. annuum foram identificados como componentes majoritários ar-tumerona e tumerona, além da curlona (Figura 7). ${ }^{50}$

Dos condimentos avaliados no trabalho, a canela apresentou melhores resultados para todas as superfícies e secreções avaliadas, seguido do condimento louro. Os condimentos cúrcuma e curry apresentaram resultados satisfatórios para revelação das impressões digitais sebáceas em ambas as superfícies, porém na avaliação das impressões digitais naturais, apenas foi possível uma elucidação satisfatória da impressão digital latente depositada na superfície de vidro. Já a páprica apresentou resultados inferiores, quando comparada aos outros condimentos, para todos os casos, em especial para revelação de impressões digitais naturais em ambas as superfícies. ${ }^{50}$ Entretanto, os autores salientam que as impressões digitais podem ter variações na composição química que podem ser

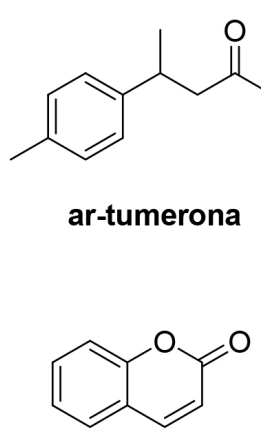

cumarina<smiles>C=CCc1ccc(O)c(OC)c1</smiles>

eugenol<smiles>O=C/C=C/c1ccccc1</smiles>

cinamaldeído<smiles>CC(C)c1ccccc1</smiles>

cumeno

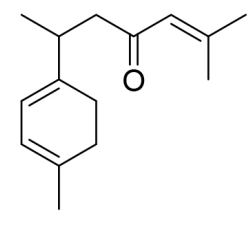

tumerona
Figura 7. Componentes químicos identificados nos temperos Curcuma longa (cúrcuma), Murraya koenigii L. (curry), Cinnamomum verum J. (canela), Laurus nobilis L. (louro) e Capsicum annuum L. (páprica)

influenciadas por características do doador, como: alimentação, sexo, idade, ancestralidade, entre outros. ${ }^{50,51}$

A eficiência de revelação dos condimentos canela, louro e cúrcuma e da alga Spirulina também foi avaliada em outros objetos comuns de superfícies lisas como garrafa de vidro, xícara, celular e cartão de crédito utilizando secreções sebáceas. Em todos os objetos foi possível observar que o pó teve um bom contraste com a superfície aplicada. $\mathrm{O}$ pó de cúrcuma forneceu um contraste amarelado na superfície da garrafa de vidro o que pode ser relacionado à presença de curcuminas como compostos majoritários. O pó de louro mostrou contraste verde na superfície da xícara, sendo constituído pelos constituintes ar-tumerona, cumeno, eugenol, curlona. A coloração verde também pode estar relacionada à presença de clorofila no pó de louro. O pó de canela utilizada para revelar o celular mostrou coloração amarela mais clara, coloração que pode estar associada à presença dos compostos ar-tumerona, cumarina, curlona, eugenol e o cinamaldeído como constituinte majoritário. O pó de Spirulina também apresentou um contraste verde na superfície do cartão. Em todas as revelações foi possível observar nitidamente as minúcias das impressões digitais (Figura 8).

É importante salientar que os condimentos avaliados são de fácil obtenção, apresentam baixo custo quando comparados a pós comerciais utilizados para revelação de impressões digitais latentes e também apresentam baixa toxicidade, viabilizando a sua utilização de forma segura. ${ }^{50}$

\section{Outras plantas terrestres e herbáceas}

Durian (Duriozi bethinus) é uma fruta sazonal popular no sudeste da Ásia, especialmente na Malásia, Indonésia, Tailândia e Filipinas. ${ }^{52}$ O Escritório Central de Estatísticas da República da Indonésia afirma que a produção média de Durian aumentou de 17.405 toneladas em 1999 para 741.831 toneladas em 2003, e no final de 2011 para 883.969 toneladas. Porém, apenas um terço dessas frutas são comestíveis, enquanto as sementes e a casca são geralmente descartadas. A utilização de sementes de Durian ainda é limitada. ${ }^{53}$

Um estudo recente utilizou sementes da fruta Durian para produzir um pó revelador de impressões digitais. ${ }^{54}$ Nesse trabalho, Sekar e 


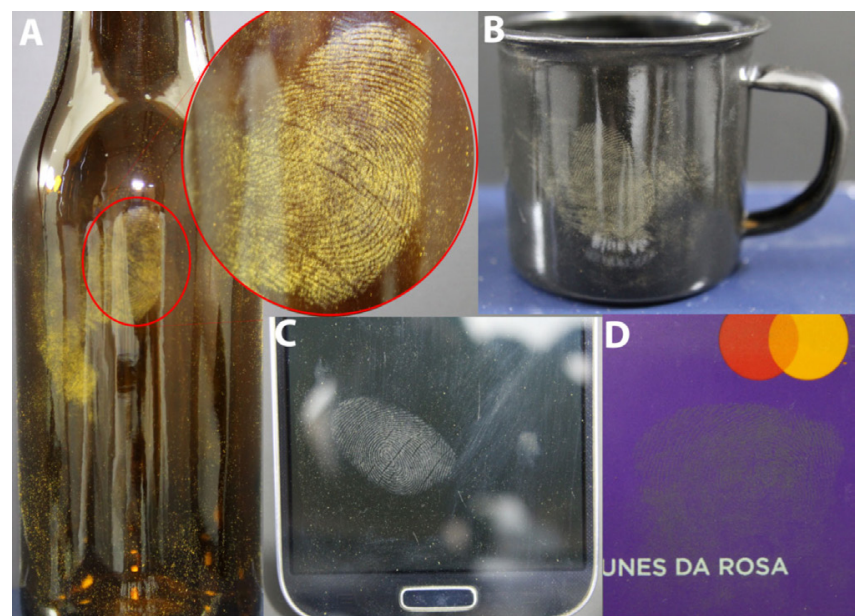

Figura 8. Impressões digitais latentes (a) garrafa de vidro revelada com pó de cúrcuma (b) xícara revelada com louro (c) celular revelado com canela (d) cartão de crédito revelado com pó da alga Spirulina

colaboradores $^{54}$ desenvolveram a revelação de impressões digitais latentes em superfícies porosas e não porosas. Para a obtenção do pó, um quilograma de sementes de Durian foi obtido em um mercado local. A camada mais externa das sementes foi removida e a parte internada foi lavada e seca por alguns dias. Em seguida, as sementes foram trituradas em um liquidificador até obter um pó fino. As superfícies utilizadas foram folha de alumínio, papel carbono, CD, espelho, aço pintado, jornal, placa de Petri, garrafa de plástico, aço, papel transparente, superfície de madeira e lâmina de microscópio. Para a coleta de impressões digitais, o doador lavou as mãos e deixou secar por $30 \mathrm{~min}$. antes da deposição. Doze impressões digitais de um mesmo doador foram depositadas em cada superfície diferente avaliada, incluindo superfícies porosas e não porosas. As impressões digitais latentes sebáceas do indivíduo doador foram coletadas friccionando os dedos no rosto e testa. O pó foi espalhado pelas superfícies analisadas pela técnica do pó até o aparecimento das impressões digitais com clareza, sendo o excesso de pó removido. As impressões digitais reveladas foram fotografas com câmera de alta resolução para obtenção das imagens.

O pó de Durian se mostrou eficaz na revelação das impressões digitais em todas as superfícies avaliadas, variando apenas na clareza das minúcias reveladas em cada superfície. Os autores descrevem que a razão para a aderência das partículas do pó das sementes de Durian às marcas papilares deve-se ao fato de que o principal componente das sementes de Durian é o amido, que é capaz de se aderir fisicamente aos componentes aquosos e oleosos presentes na impressão digital. Ainda apontam a possível formação de ligação de hidrogênio entre os ácidos graxos/glicerídeos contidos nas impressões digitais e aos grupos carbonila e hidroxila dos componentes do pó das sementes de Durian. Ressalta-se que o pó das sementes de Durian não é indicado para superfícies de coloração clara, pois a coloração do pó é branca, ocasionando, portanto, falta de contraste para visualização em tais suportes. ${ }^{54}$

Henna, um produto natural proveniente das folhas de Lawsonia inermis, de maneira análoga a genipina, foi usada como tintura para pele e cabelo por milênios, com relatos de seu uso datando de $1400 \mathrm{aC} .{ }^{55}$ Acredita-se que o composto responsável pelas propriedades de coloração da henna é a lawsona (Figura 9). ${ }^{55}$ A lawsona é uma naftoquinona (2-hidroxi-1,4-naftoquinona), um grupo de compostos conhecido por suas reações com aminoácidos. Os aminoácidos são componentes muito importantes em secreções de impressões digitais e são particularmente importantes em superfícies porosas, como o papel, e tendem a se ligar as fibras do papel. ${ }^{56}$
Devido às importantes características da lawsona, Jelly e colaboradores $^{56}$ investigaram a capacidade da lawsona na revelação de impressões digitais latentes. As impressões digitais foram coletadas em um filtro de papel de um número de diferentes voluntários. Os doadores foram orientados a não lavar suas mãos imediatamente antes de coletar as impressões digitais. As tiras de papel filtro foram então mergulhadas na solução de lawsona, secas ao ar e aquecidas tanto em forno ou por calor direto usando uma prensa. Os experimentos iniciais com lawsona em solução etanólica produzindo marcas desenvolvidas em cor marrom-púrpura que também exibiram forte fotoluminescência quando iluminados com uma fonte de luz forense a $555 \mathrm{~nm}$ e visualizados com óculos vermelhos. Nesses ensaios, observou-se que o etanol levava a uma significativa descoloração do papel, resultando em perda na qualidade da imagem. Para os demais ensaios, a lawsona $(500 \mathrm{mg})$ foi dissolvida em acetato de etila (10 $\mathrm{mL}$ ) e a solução resultante foi subseqüentemente misturada com metil nonafluoroisobutil éter (40 mL). Então, o papel filtro contendo as impressões digitais foi mergulhado nessa solução, seco ao ar livre e então revelado com calor. $\mathrm{O}$ aquecimento em forno por 1 hora a $140-170{ }^{\circ} \mathrm{C}$ produziu uma revelação mais uniforme do que com o uso da prensa, sendo possível a visualização completa de todos os detalhes das cristas papilares.<smiles>O=C1C=C(O)C(=O)c2ccccc21</smiles>

lawsona

Figura 9. Estrutura química de lawsona

Outro estudo realizado por Phungyimnoi e colaboradores ${ }^{57}$ relata a utilização de lawsona na técnica de vaporização a vácuo. O método testou amostras de papel térmico pendurados 5,10 e $15 \mathrm{~cm}$ acima de uma fonte de aquecimento com sólidos de lawsona dispersos em uma câmara de vácuo. As condições otimizadas para sublimação de lawsona foram de 50, 100 e $150 \mathrm{mg}$ e temperatura de vaporização de $40-60^{\circ} \mathrm{C}$. As impressões digitais foram envelhecidas por 1, 3, $7 \mathrm{e}$ 30 dias antes de fazer os testes. Os resultados mostraram que usando $100 \mathrm{mg}$ de lawsona para sublimação a uma distância de $10 \mathrm{~cm}$ do papel térmico, foi possível visualizar minúcias claras e detectáveis que podem ser usadas para identificação de impressões latente no Sistema Automatizado de Identificação de Impressões Digitais (AFIS). Essa técnica não envolve o uso de solventes e materiais perigosos e tem baixo custo, podendo ser interessante para revelação de impressões digitais em superfícies claras, já que a coloração da amostra fica entre preta e roxo escuro. ${ }^{57}$

Tradicionalmente usado como erva natural, o gambir é extraído das folhas e galhos da Uncaria gambir, planta de Roxburgh, nativa do Sri Lanka, Indonésia e Malásia.$^{58}$ Além de ser comumente usada como remédio para aliviar doenças inflamatórias da pele e dores de cabeça, o gambir, que varia do amarelo ao marrom, também é usado como corante têxtil e agente bronzeador. ${ }^{59}$

Devido a sua ampla e fácil disponibilidade, baixa toxicidade assim como produção simples o pó de gambir é uma atraente alternativa como revelador de impressão digital. Nesse sentido, Sari e colaboradores ${ }^{60}$ elaboraram uma pesquisa que visou desenvolver um pó natural e barato para revelar impressões digitais latentes em suportes secos não porosos como, folha de alumínio, vidro, copos plásticos, discos compactos e plásticos transparentes. Esses materiais foram escolhidos no intuito de simular a superfície metálica e brilhante de armas como facas ou óculos ou evidências comumente 
encontradas em cenas de crime. O gambir extraído das frutas de plantas da espécie $U$. gambir foi obtido em um comercio local de Medan. Com o uso de almofariz e pilão, aproximadamente $500 \mathrm{~g}$ de gambir foi moído e peneirado em diferentes tamanhos de partícula $(0,250,0,177,0,149$ e $0,125 \mathrm{~mm})$ e em seguido os respectivos pós foram armazenados. Nos ensaios de deposição de impressão digital latente, um total de sessenta impressões digitais foram depositadas nos cinco materiais de estudo. Para cada superfície e tamanho de partículas, amostras em triplicata foram coletadas e etiquetas individualmente. Depois da deposição, as impressões digitais foram mantidas em temperatura ambiente $\left(28-30^{\circ} \mathrm{C}\right)$ por duas horas. Após serem reveladas as impressões digitais foram fotografadas.

Os resultados dessa pesquisa revelaram que a qualidade das imagens obtidas em superfícies de vidro e plásticos transparentes foram superiores ao utilizar o pó de gambir relativamente grosso $(0,250 \mathrm{~mm})$ ao invés dos pós com tamanhos de partícula menores. Além disso, observou-se que as imagens obtidas em lâminas de vidro se mostraram inferiores quando comparados com plástico transparentes, o que pode ser atribuído a superfície relativamente lisa do vidro resultante de uma aderência mais fraca dos constituintes da impressão digital ricos em constituintes sebáceos. No entanto, em outras superfícies como copos de plástico, discos compactos folhas de alumínio, os pós com partículas mais finas mostraram-se mais eficazes na revelação de impressão digital, sendo que a qualidade das imagens foi melhor com o aumento da rugosidade das superfícies. ${ }^{60}$

A Imperata cylindrica é uma espécie de grama perene comum em países tropicais encontrada principalmente em terrenos degradados ou solo que não é cuidado de forma adequada. Essa erva daninha tem sido usada como matéria-prima de baixo custo para a preparação de carvão ativado para tratar águas residuais industriais contendo metais pesados ${ }^{61}$ Low e colaboradores ${ }^{7}$ desenvolveram um novo pó revelador de impressões digitais utilizando o pigmento em pó de Imperata cylindrica modificado com ácido. A ideia de usar o pó modificado foi baseada na reação de adesão entre o ácido e as cristas papilares, bem como a formação de ligações hidrogênio entre o grupo hidroxila e carbonila do pó e os ácidos graxos ou glicerídeos da parte oleosa das amostras, fazendo com que elas fiquem pretas quando entram em contato.

A espécie em estudo foi coletada em um terreno abandonado em Penão na Malásia. O material coletado foi limpo e seco sob luz do sol. Em seguida o material foi moído, lavado com água destilada em ebulição até a solução residual se tornar clara e foi seco em forno a $100{ }^{\circ} \mathrm{C}$. Então, $1 \mathrm{~g}$ do pó foi misturado com $1 \mathrm{~mL}$ do ácido sulfúrico $\left(95-98^{\circ} \mathrm{C}\right)$. A mistura foi seca a $100{ }^{\circ} \mathrm{C}$ por $24 \mathrm{~h}$. Posteriormente o pó foi lavado com água fervente e foi mantido em solução de bicarbonato de sódio $1 \%$ durante a noite para remoção do excesso de ácido. Depois lavado por repetidas vezes com água destilada fervente até atingir o pH 7. O pó foi seco a $100{ }^{\circ} \mathrm{C}$ e peneirado. Nos testes de revelação de impressão digital foram avaliados o pó de $I$. cylindrica e o pó de I. cylindrica modificado com ácido. Foram coletadas as secreções naturais, écrinas e sebáceas de seis doadores em superfícies em papel branco A4, plástico branco, metal e vidro a fim de avaliar a interação dos pós de I. cylindrica com as diferentes secreções. Também foram avaliadas impressões digitais envelhecidas de 1, 7 e 14 dias em superfícies de metal e plástico branco e impressões submergidas em água em períodos de 24,48 e $72 \mathrm{~h}$. A qualidade das imagens obtidas foi comparada com o pó comercial preto Hi-Fi da Sirchie ${ }^{\circledR}$.

O pó de I. cylindrica foi selecionado nesse estudo pois ele adere na ponta dos dedos, fazendo com que a pele do dedo fique preta quando entra em contato. O pó se mostrou eficiente na revelação de impressões digitais écrinas e sebáceas em papel A4 e plástico. No entanto, o pó de I. cylindrica não modificado falhou na revelação de secreções écrinas em papel A4. ${ }^{7}$
Além disso, os resultados envolvendo impressões sebáceas em papel A4 e impressões écrinas em plástico revelaram que o pó de $I$. cylindrica não modificado não mostrou todos os detalhes de crista papilares com clareza nos ensaios de revelação. A razão da maior eficiência do pó de I. cylindrica em relação ao não modificado pode estar relacionado a diferença de área superficial dos pós, onde a área superficial encontrada do pó de I. cylindrica modificado foi de $8,15 \mathrm{~m}^{2} \mathrm{~g}^{-1}$ enquanto o pó não modificado apresentou $0,91 \mathrm{~m}^{2} \mathrm{~g}^{-1}$. Os autores sugerem também que a aderência do pó modificado pode estar relacionada à formação de ligação hidrogênio entre a hidroxila e carbonila do pó e ácidos graxos e glicerídeos das secreções sebáceas. ${ }^{7}$

Nos demais ensaios subseqüentes mostraram que o pó $I$. cylindrica modificado mostrou uma boa aderência aos constituintes écrinos e sebáceos contidos na impressão digital em superfície de papel A4, metal, plástico e vidro. Além disso, foi possível notar que as impressões digitais sebáceas reveladas com o pó mostraram maior contraste em relação à superfície aplicada quando comparadas com as écrinas. ${ }^{7}$

Os ensaios de revelação com o pó utilizando impressões digitais envelhecidas mostraram que detalhes das cristas papilares mais claras foram obtidas do dia 1 ao 7 comparadas ao dia $14 \mathrm{em}$ ambas as superfícies avaliadas (metal e plástico). Assim, observa-se que os detalhes das cristas se tornaram menos evidentes à medida que $o$ tempo da marca aumentou, o que ocorre, pois os componentes oleosos e úmidos evaporam ao longo do tempo e assim o pó adere menos nas cristas papilares. ${ }^{7}$ Nos ensaios de impressões digitais submergidas, notou-se que medida que o tempo da exposição das impressões em água aumentou os distintos detalhes de cristas ainda podiam ser observados em superfícies de metal e plástico. ${ }^{7}$

A análise comparativa entre o pó preto Hi-Fi da Sirchie ${ }^{\circledR}$ e o pó de I. cylindrica modificado, demonstrou que o último apresentou qualidade e sensibilidade menores. Os autores salientam que pesquisas futuras irão focar no desenvolvimento do pó $I$. cylindrica modificado com menor tamanho de partícula. No entanto, os autores salientam que o pó desenvolvido foi eficaz na visualização das impressões digitais com boa qualidade nos detalhes de cristas papilares. ${ }^{7}$

Sari e colaboradores ${ }^{62}$ também avaliaram um pó natural extraído das cascas da fruta do dragão (Hylocereus undatus) também conhecida como pitaia pelo seu desempenho na revelação de impressões digitais latentes. Essa espécie pertence à família Cactaceae, sendo nativa do México e América do Sul e Central. ${ }^{63}$ Possui grande valor econômico e é conhecida pelos seus efeitos benéficos a saúde. A casca da pitaia representa 30-35\% do peso do fruto e muitas vezes é descartada como lixo. É utilizada em alimentos funcionais, geléias e em aditivos em sorvetes devido à presença de pigmentos naturais que podem ser usados em substituição aos corantes sintéticos. A casca dessa fruta contém grande quantidade de pigmentos como as antocianinas. ${ }^{62,63}$

Nesse estudo, a casca da fruta pitaia foi cortada em pedaços menores e seca em forno a $30-38^{\circ} \mathrm{C}$. Em seguida o material foi moído e peneirado obtendo o pó com 60, 80, 100 e 200 mesh. Para a coleta das impressões digitais, o doador friccionou os dedos no rosto e testa a fim de enriquecer os dedos com secreções sebáceas e realizar as deposições nas respectivas superfícies. O método do empoamento foi utilizado na revelação das impressões digitais em superfícies não porosas (folha de alumínio, CD e vidro) e o excesso de pó foi removido. Já nos ensaios de revelação envolvendo superfícies porosas (papel HVS, papel espectral e papelão), $50 \mathrm{mg}$ do pó de pitaia foi dissolvido em $10 \mathrm{~mL}$ de acetato de etila e depois dissolvendo em $40 \mathrm{~mL}$ de éter de petróleo. As amostras de impressão digital foram submersas nessa solução, depois aeradas e secas em um forno a $150{ }^{\circ} \mathrm{C}$ por $1 \mathrm{~h} .{ }^{62}$

As imagens de revelação obtidas com o pó pitaia com 100 e 200 mesh mostraram claras e com bom contraste com superfícies 
de folha de alumínio e vidro. No entanto, ao utilizar os pós de 60 e 80 mesh a visualização das minúcias não foi boa o suficiente. Os autores salientam que o pó mais fino entra mais em contato com a superfície onde a marca está depositada e dessa forma é mais fácil identificar os padrões/linhas das impressões digitais. Na superfície do $\mathrm{CD}$, a visualização das imagens não se mostrou boa, pois o pó não aderiu muito bem a esse tipo de superfície. Observou-se também que quanto menor a partícula maior foi à adesão do pó a superfície. ${ }^{62}$

A revelação de impressões digitais latentes em superfícies de papel requer revelação com uma solução reagente seja por imersão ou spray. As impressões digitais em superfície de papel HVS, papel espectral e papelão foram reveladas por submersão em uma solução de pitaia seguido por secagem das superfícies, porém os padrões de linhas de fricção não se mostraram totalmente visíveis. Além disso, o aquecimento prolongado da superfície resultou em perda de contraste das impressões digitais, além da superfície de fundo escurecer com o aquecimento. ${ }^{62}$

Com base nesses resultados, fica evidente que o tipo de superfície adotada, o tamanho das partículas do pó, tipo e quantidade de resíduo da pele são fatores que podem afetar a eficiência de revelação. O pó de pitaia mostrou-se eficiente na revelação de impressões digitais latentes em superfícies de folha de alumínio e vidro ao utilizar pós com 100 e 200 mesh. Considerando que muitas vezes a casca de pitaia é descartada, seu pó pode ser uma excelente alternativa natural e economicamente viável na revelação de impressões digitais latentes. ${ }^{62}$

\section{PERSPECTIVAS}

O desenvolvimento de reveladores de impressões digitais latentes é um capítulo à parte na América latina. No Brasil, há uma diferença estrutural significativa dentre as perícias científicas da Polícia Federal com Institutos Gerais de Perícia oriundos de Polícia Estaduais. Em regiões mais longínquas, materiais adequados e reagentes químicos têm sido um diferencial e em muitas vezes os peritos e papiloscopistas precisam utilizar da criatividade para a execução da revelação digital. Pós de corantes tradicionais, similares a toner de impressora, ainda são empregados, pois o alto custo de importação dos reveladores de impressões digitais dificulta a disponibilidade desse material. Embora pós de impressora apresentem uma visualização satisfatória das minúcias, eles não são adequados pela questão da reprodutibilidade e também pela qualidade da revelação de impressão digital latente.

A disponibilidade de reveladores de impressões digitais não é uma realidade de todos os laboratórios periciais e de pesquisa no Brasil. A pesquisa e o desenvolvimento tecnológico tem sido uma perspectiva positiva em nossos laboratórios mediante a existência do INCT-Forense que permite o compartilhamento de expertises da Polícia e Papiloscopia, Polícia Federal com a Ciência desenvolvida em Universidade Pública. ${ }^{64-68}$ Essa perspectiva tornou possível a otimização de instrumentações analíticas, como a Espectrometria de Fluorescência por energia dispersiva EDX e Espectroscopia de Infravermelho que puderam ser focadas para as pesquisas forenses. Para o desenvolvimento de reveladores de impressões digitais com origem nacional alguns avanços na química devem ser considerados. Uma tendência científica e tecnológica compreende a incorporação de nanopartículas em substâncias químicas orgânicas e minerais, que podem originar compostos híbridos com propriedades particulares para reveladores de impressões digitais latentes como otimização da cor, aperfeiçoamento de adesão a superfície e fluorescência. ${ }^{69}$

Nesse sentido, outros avanços na ciência que estudam os traços químicos de impressões digitais de origem endógena e exógena ressaltam a aplicação espectroscópica, como uso de ferramentas rebuscadas para a química forense e papiloscopia como a Microscopia
Raman, Microscopia de Infravermelho, Espectroscopia de Fluorescência, Dessorção e Ionização a Laser assistidos por superfície (SALDI-MS) e Ionização e Dessorção a Laser assistidos por matriz de tempo de vôo (MALDI-TOF) ${ }^{69}$ No Universo da Química Orgânica, a aplicação de moléculas clássicas, chalconas, curcuminas, pirazóis e heterociclos é uma realidade. . $^{1064,66-68}$

Entretanto, produtos naturais como as algas e a cúrcuma são matérias primas excepcionais para a aplicação como reveladores de impressões digitais, logicamente condicionados à adição de tecnologias, às vezes clássicas como a formulação farmacêutica, ou mesmo aliados à síntese de compostos nanoestruturados. Os produtos naturais precisam ser valorizados e avaliados numa ótica sustentável na sua composição original, levando em conta compostos orgânicos e inorgânicos.

No campo da Educação em Química os materiais alternativos compõem uma oportunidade ímpar para a pesquisa de métodos opcionais eficazes para o ensino de Química Forense empregando reagentes de baixo custo, seguros e sustentáveis e sempre enfatizando conceitos relevantes para o estudante como ligação química, interações intermoleculares, funções orgânicas, compostos bioquímicos (ácidos graxos, aminoácidos) e Cromatografia. ${ }^{50}$ Enfim, os reveladores de impressões digitais oferecem oportunidades concomitantes para educação em Química, desenvolvimento científico e inovação tecnológica.

\section{CONCLUSÕES}

A coleta de impressões digitais por órgãos periciais em uma cena de crime é de fundamental relevância para identificação humana. As impressões digitais latentes necessitam de métodos adequados de revelação para que possam ser visualizadas. A técnica do empoamento é o método mais comumente utilizado na detecção de impressões digitais latentes, no entanto, há uma grande carência por pós que apresentem uma revelação nítida em diferentes tipos de superfícies e que apresente baixa toxicidade ao manuseio humano. De acordo com os estudos apresentados neste trabalho, os pós provenientes de produtos naturais mostraram similar eficácia dos pós reveladores disponíveis no mercado, sendo possível observar claramente as minúcias e mostraram boa revelação em diferentes superfícies. Além disso, a utilização de produtos naturais em pós reveladores é muito viável, uma vez que essa matéria prima é encontrada facilmente, apresenta um preço de aquisição mais acessível e apresenta toxicidade consideravelmente menor em relação aos reveladores tradicionais. Portanto, os produtos naturais podem ser uma matéria prima alternativa com aplicação na revelação de impressões digitais em investigações forenses.

\section{AGRADECIMENTOS}

Os autores agradecem ao Instituto Nacional da Ciência e Tecnologia (INCT Forense-CNPq 465450/2014-8) pela assistência técnica e recursos. Este trabalho faz parte do projeto "Reveladores e Marcadores Forenses: Obtenção Química e Propriedades - 8634". Os autores agradecem também à FAPERGS e à Coordenação de Aperfeiçoamento de Pessoal de Nível Superior - Brasil (CAPES) Código Financeiro 001.

\section{REFERÊNCIAS}

1. Becue, A.; Moret, S.; Champod, C.; Margot, P.; Biotech. Histochem. 2011, 86, 140.

2. Arshad, A.; Farrukh, M. A.; Ali, S.; Khaleeq-ur-Rahman, M.; Tahir, M. A.; J. Forensic Sci. 2015, 60, 1182. 
3. Dam, A. V.; Van Weert, A.; Falkena, K.; Weymans, C.; Kloosterman, A.; Lambrechts, S. A. G.; Van Leeuwen, T. G.; Aalders, M. C. G.; Anal. Methods 2018, 10, 1413.

4. Lee, H. C.; Gaensslen, R. E.; Em Advances in Fingerprint Technology; Lee, H. C., Gaensslen, R. E., eds.; CRC Press: Boca Raton, 2001, cap.4.

5. Mariotti, K. C.; Brazilian Journal of Forensic Sciences, Medical Law and Bioethics 2020, 9, 210.

6. Sodhi, G. S.; Kaur, J.; Forensic Sci. Int. 2001, 120, 172.

7. Low, W. Z.; Khoo, B. E.; Aziz, Z. B. A.; Low, L. W.; Teng, T. T.; Abdullah, A. F. L.; Sci. Justice 2015, 55, 347.

8. Garg, R. K.; Kumari, H.; Kaur, R.; Egypt. J. Forensic Sci. 2011, 1, 53.

9. Holder Jr, E. H.; Robinson, L. O.; Laub, J. H.; Em The fingerprint Sourcebook; Yamashita, B., French, M., eds.; National Institute of Justice: Washington, 2011, cap 7.

10. Pacheco, B. S.; Da Silva, C. C.; Da Rosa, B. N.; Mariotti, K. C.; Nicolodi, C.; Poletti, T.; Segatto, N. V.; Collares, T.; Seixas, F. K.; Paniz, O.; Carreno, N. L. V.; Pereira, C. M. P.; Chem. Pap .(2021), doi:10.1007/ s11696-021-01556-4.

11. Delgado-Vargas, F.; Jiménez, A. R.; Paredes-López.; Crit. Rev. Food Sci. Nutr. 2000, 40, 173

12. Passos, L. F.; Berneira, L. M.; Poletti, T.; Mariotti, K. C.; Carreño, N. L. V; Hartwig, C. A.; Pereira, C. M. P.; Aust. J. Forensic Sci. 2020, 32, 3319.

13. Viegas Jr, C.; Bolzani, V. S.; Barreiro, E. J.; Quim. Nova 2006, 29, 326.

14. Lameira, O. A.; Pinto, J. E. B. P. Plantas Medicinais: do Cultivo, Manipulação e uso à Recomendação Popular, 1ª ed., Embrapa: Pará, 2008.

15. Goel, A.; Kunnumakkara, A. B.; Aggarwal, B. B.; Biochem. Pharm. 2008, 75, 787.

16. Pinto, A. C.; Quim. Nova 1995, 18, 608.

17. Garcia, C. E. R.; Bolognesi, V. J.; Dias, J. F. G.; Miguel, O. G.; Costa, K. C.; Cienc. Rural 2012, 42, 8.

18. Almeida, M. R; Martinez, S. T; Pinto, A. C.; Rev. Virtual Quim. 2017, 9 , 3.

19. Silva, C. E. S.; dos Santos, O. J.; Ribas-Filho, J. M.; Tabushi, F. I.; Kume. M. H.; Jukonis, L. B.; Cella, I. G.; Rev. Col. Bras. Cir. 2015, 42, 6.

20. Náthia-Neves, G.; Nogueira, G. C.; Vardanega, R.; Meireles, M. A. A.; Food Sci. Technol. 2018, 38, 116.

21. Djerassi, C.; Nakano, T.; James, A. N.; Zalkow, L. H.; Eisenbraun, E. J.; Shoolery, J. N.; J. Org. Chem. 1961, 26, 1192.

22. Singh, O.; Khanam, Z.; Misra, N.; Srivastava, M. K.; Pharmacogn. Rev. 2011, 5, 82 .

23. Schoefs, B.; Trends Food Sci. Technol. 2002, l3, 361.

24. Britton, G.; Em UV/Visible Spectroscopy; Britton, G., Liaaen-Jensen, S., Pfander, H., eds.; Birkhäuser Verlag: Basel, 1995, cap. 2.

25. Ferrão, J. E. M.; A aventura das plantas e os descobrimentos portugueses, $2^{a}$ ed., Fundação Berardo: Lisboa, 1992.

26. King, R. S. P.; Hallett, P. M.; Foster, D.; Forensic Sci. Int. 2015, 249, 21.

27. Scott, S. A.; Davey, M. P.; Dennis, J. S.; Horst, I.; Howe, C. J.; LeaSmith, D. J.; Smith, A. G.; Curr. Opin. Biotechnol. 2010, 21, 277.

28. Suganya, T.; Varman, M.; Masjuki, H. H.; Renewable Sustainable Energy Rev. 2016, 55, 909.

29. Andrade, P. B.; Barbosa, M.; Pedro, R.; Lopes, G.; Vinholes, J.; Mouga, T.; Valentão, P.; Food Chem. 2013, 138, 1819

30. Larkum, A. W. D.; Douglas, S. E.; Raven, J. A. Em Photosynthesis in Algae: Biochemical and Physiological Mechanisms; Larkum, A. W. D., Douglas, S. E., Raven, J. A., eds.; Springer: Cham, 2003, cap. 1.

31. Kim, J. K.; Jo, C.; Hwang, H. J.; Park, H. J.; Kim, Y. J.; Byun, M. W.; Radiat. Phys. Chem. 2006, 75, 449.

32. Shirsath, S. R.; Sable, S. S.; Gaikwad, S. G.; Sonawane, S. H.; Saini, D. R.; Gogate, P. R.; Ultrason. Sonochem. 2017, 38, 437.

33. Da Silva, C. C..; Pacheco, B. S.; Neves, R. N.; Dié Alves, M. S.;
Sena-Lopes, A.; Moura, S.; Borsuk, S.; Pereira, C. M. P.; Biomed. Pharmacother. 2019, 111, 367.

34. Do Amaral, C. C. F.; Pacheco, B. S.; Seixas, F. K.; Pereira, C. M. P.; Collares, T.; Algal Res. 2020, 48, 101936.

35. Sharma, O. P.; Biochem. Pharmacol. 1976, 25, 1811.

36. Yang, Q. Q.; Cheng, L. Z.; Zhang, T.; Yaron, S.; Jiang, H. X.; Sui, Z. Q.; Corke, H.; Ind. Crops Prod. 2020, 152, 112561.

37. Sebastiany, A. P.; Pizzato, M. C.; Del Pino, J. C.; Salgado, T. D. M.; Educ. Quim. 2013, 24, 49.

38. Yamashita, B.; French, M.; Bleay, S.; Cantu, A.; Inlow, V.; Ramotowski, R.; Sears, V.; Wakefield, M.; Latent Fingerprint Examination: Elements, Human Factors and Recommendations, Nova Science Publishers Inc.: Hauppauge, 2014. pp. 225-320.

39. Jasuja, O. P.; Kaur, A.; Kumar, P.; Forensic Sci. Int. 2012, 223, 47.

40. Becue, A.; Moret, S.; Champod, C.; Margot, P.; Biotech. Histochem. 2011, 86, 140.

41. Poletti, T.; Moraes, L.; Passos, L.; Rosa, B. N.; Pereira, C. M. P.; Mariotti, K. C.; Sci. Justice 2021, 61, 378.

42. Frick, A. A.; Chidlow, G.; Lewis, S. W.; Van Bronswijk, W.; Forensic Sci. Int. 2015, 254, 133

43. Pleik, S.; Spengler, B.; Schäfer, T.; Urbach, D.; Luhn, S.; Kirsch, D.; J. Am. Soc. Mass Spectrom. 2016, 27, 1565.

44. Velho, J. A.; Geiser, G. C.; Espindula, A. Em Ciências Forenses: Uma introdução às principais áreas da criminalística moderna; Figini, A. R. L., ed.; Millenium: São Paulo, 2017, cap. 8.

45. Archer, N. E.; Charles, Y.; Elliott, J. A.; Jickells, S.; Forensic Sci. Int. 2005, 154, 224.

46. Adhithya, R.; Suneetha, V.; Pharm. Lett. 2015, 7, 325.

47. Saran, V. S.; Kesharwani, L.; Gupta, A. K.; Mishra, M. K.; IJournals: International Journal of Social Relevance \& Concern (IJSRC) 2015, 3, 8.

48. Santos, L. M. O.; De Oliveira, L. A.; Tibulo, E. P. S.; De Lima, C. P.; Rev. Cienc. Farm. Basica Apl. 2015, 36, 251.

49. Mazaro, S. M.; Fogolari, H.; Wagner Jr., A.; Citadin, I.; Santos, I.; Rev. Bras. Plant. Med. 2013, 15, 208.

50. Nicolodi, C.; Rosa, B.; Silva, C.; Berneira, L.; Pacheco, B.; Poletti, T.; Venzke, D.; Mariotti, K.; Pereira, C.; Quim. Nova 2019, 42, 962.

51. Cadd, S.; Islam, M.; Manson, P.; Bleay, S.; Sci. Justice 2015, 55, 219.

52. Mirhosseini, H.; Amid, B. T.; Chem. Cent. J. 2013, 103, 7, 1.

53. Cornelia, M.; Siratantri, T.; Prawita, R.; Procedia Food Sci. 2015, 3, 1.

54. Sekar, M.; Zulkifli, N. F.; Indo Am. J. Pharm. Sci 2017, 4, 2362.

55. Petkewich, R.; Chem. Eng. News 2006, 84, 28.

56. Jelly, R.; Lewis, S. W.; Lennard, C.; Lim, K. F.; Almong, J.; Chem. Commun. 2008, 1, 3513.

57. Phungyimnoi, G.; Eksinitkun, G.; Phutdhawong, W.; J. Phys.: Conf. Ser. 2017, 901, 012159.

58. Zhao, Y.; Kim, Y, H.; Lee, W.;Lee, Y. K.; Kim, K. T.; Kang, J. S.; Pharmaceut. Biomed. 2016, 117, 73.

59. Anggraini, T.; Tai, A.; Yoshino T.; Afr. J. Biochem. Res. 2011, 5, 1.

60. Sari, S. A.; Ningsih, H.; Jasmidi, A. K.; Mahat, N. A.; AIP Conf. Proc. 2019, 020023, 1.

61. Hanafiah, M. A. K. M.; Zakaria, H.; Ngah, W. S. W.; CLEAN-Soil, Air, Water 2010, 38, 248.

62. Sari, S. A.; Lubis, A. N. S.; Jurnal Kimia Dan Pendidikan Kimia 2021, $6,1$.

63. Cheah, L. K.; Eid, A. M.; Aziz, A.; Ariffin, F. D.; Elmahjoubi, A.; Elmarzugi, N. A.; Nanomed. Nanotechnol. 2016, 1, 000103.

64. Rosa, B. N.; Venzke, D.; Poletti, T.; Lima, N.; Camacho, J.; Mariotti, K.; Dos Santos, M.; Pizzutti, L.; Carreño, N.; Pereira, C. M. P.; J. Braz. Chem. Soc. 2020, 31, 1327.

65. Venzke, D.; Poletti, T.; Rosa, B. N.; Berneira, L. M.; De Lima, N. P. K.; De Oliveira, T. F.; Carreño, N. L. V.; Mariotti, K. C.; Duarte, L. S.; Nobre, S. M.; Pereira, C. M. P.; Chem. Data Collect. 2021, 33, 100680. 
66. Rosa, B. N.; Mariotti, K. C.; Pacheco, B. S.; Silva, C. C.; Carreño, N. L. V.; Nicolodi, C.; Poletti, T.; Silva, A. C. A.; Silva, A. F.; Giongo, J. L.; Vaucher, R. A.; De Oliveira, T. F.; Pereira, C. M. P.; Chem. Data Collect. 2021, 33, 100700

67. Pereira, C. M. P.; Silva, A. C. A.; Nicolodi, C.; Ros, B. N.; Borja, L. S.;
Passos, L. F.; Araújo, L. M.; Poletti, T.; Ritter, M.; Nascente, P. S.; BR PI BR10202000861, 2020.

68. Balsan, J.; Rosa, B.; Pereira, C. M. P.; Santos, C.; Quim. Nova 2019, 42, 845.

69. Wei, Q.; Zhang, M.; Ogorevc, B.; Zhang, X.; Analyst 2016, 141, 6172. 